\title{
Familial bilateral multiple fibroadenomas of the breast
}

\author{
V. Naraynsingh and G.C. Raju \\ Departments of Surgery and Pathology, Port-of-Spain General Hospital, Trinidad, West Indies.
}

\begin{abstract}
Summary: This paper describes multiple breast fibroadenomas in three siblings. It appears that the familial disorder seen is associated with bilateral multiple fibroadenomas.
\end{abstract}

\section{Introduction}

Fibroadenoma is the commonest tumour of the breast in black females (Oluwole \& Freeman, 1979), while it ranks third among breast lesions in Caucasians (Haagensen, 1971). In spite of this high incidence, the first case report on the familial character of fibroadenoma was in 1971 by Haagensen. Nigro \& Orgen (1976) in an epidemiological study, found that $27 \%$ of patients with fibroadenoma had a family history of this neoplasm. This paper constitutes the first report of multiple bilateral breast fibroadenomas in three siblings.

\section{Case reports}

Case 1

A 28 year old East Indian female, gravida 3, presented with multiple bilateral breast masses. She had first noticed 2 lumps in the left breast and 1 in the right, $4 \mathrm{y}$ before. Thereafter the number, as well as the sizes, increased and, on examination, she had 14 classical fibroadenomas in the right and 9 in the left breast. These were so mobile that all 23 tumours were easily removed via a circumareolar incision in each breast (Figure 1).

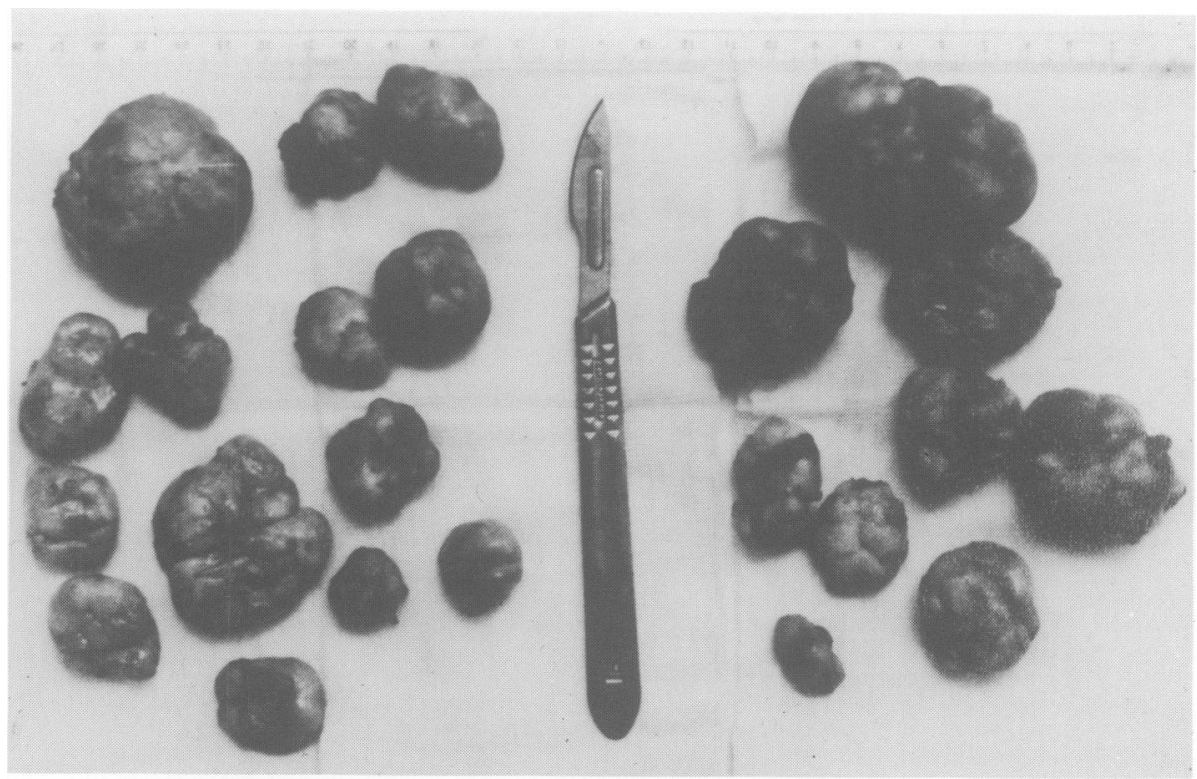

Figure 1 Multiple bilateral fibroadenomata seen in Case 1.

Correspondence: V. Naraynsingh, F.R.C.S.

Accepted: 20 July 1984

(C) The Fellowship of Postgraduate Medicine, 1985 
Case 2

Six weeks later her 22 year old sister presented with 6 breast lumps, 4 in the right and 2 in the left. She had noticed them for the previous $2 y$. On excision these were classical fibroadenomas.

Case 3

The third sister, aged 24, had bilateral fibroadenomas excised. Three lumps were removed from the left and one from the right breast. There was no evidence of tumour recurrence.

Four other sisters aged 32, 21, 18 and 16 have no breast lumps. The mother had no history of breast disease.

\section{References}

HAAGENSEN, C.D. (1971). Diseases of the Breast, 2nd ed., p. 212. W.B. Saunders, Philadelphia.

LEGAL, Y. (1961). Adenomas of the breast: relationship of adenofibromas to pregnancy and lactation. American Surgeon, 27, 14.

NIGRO, D.M. \& ORGEN, C.H. (1976). Fibroadenoma of the female breast: some epidemiologic surprises. Postgraduate Medicine, 59, 113.

\section{Discussion}

There is some evidence that multiple breast fibroaden omas may be caused by the use of hormonal cone traceptives (Weigenstein et al., 1971). However, none. of our 3 patients had ever used these hormones. I突 addition, there appears to be a statistically significanf relationship between parity and fibroadenomas of the breast (LeGal, 1961; Nigro \& Orgen, 1976). Patient was nulliparous when she developed 6 breast masse while Patient 3 had one child when she noticed 4 breasf lumps. It seems likely that the causation in these three siblings is related to a familial predispositon. Furthe $\vec{B}$ reports and careful epidemiological study may be of value in clarifying the familial nature of this disorder

OLUWOLE, S.F. \& FREEMAN, H.P. (1979). Analysis of benign breast lesions in blacks. American Journal of Surgery, 137 786.

WEIGENSTEIN, L., TANK, R.\& GOULD, V.E. (1971). Multiple breast fibroadenomas in women on hormonal contraceptives. New England Journal of Medicine, 284, 676. 